\title{
МОДЕЛИРОВАНИЕ И ОЦЕНКА МАРКЕТИНГОВОГО ПОТЕНЦИАЛА РЕГИОНА
}

\author{
(C) 2021 Назарова Эльмира Аляровна \\ аспирант Высшей школы сервиса и торговли \\ Института промышленного менеджмента, экономики и торговли \\ Санкт-Петербургский политехнический университет Петра Великого, Россия, Санкт-Петербург \\ E-mail: nazarova_ea@spbstu.ru
}

Статья посвящена моделированию и оценке маркетингового потенциала региона. Регион рассматривается как товар. Выделены элементы комплекса регионального маркетинга. Разработана модель компонентов маркетингового потенциала региона. Предложен авторский подход к оценке маркетингового потенциала региона. Обозначены возможные сценарии его применения.

Ключевые слова: маркетинг, регион, потенциал, маркетинговый потенциал, региональный потенцииал, маркетинговый потенциала региона, маркетинг региона, региональный комплекс маркетинга.

Маркетинг региона представляет собой одну из важнейших составных частей региональной политики. Сущность регионального маркетинга состоит в создании и укреплении отношений между регионом и его субъектами, являющимися взаимовыгодными, для поддержания в дальнейшем конкурентоспособности региона.

Маркетинг региона направлен на выявление, анализ и удовлетворение потребностей региональных субъектов. Он базируется на учете собственных интересов региона с целью решения плановых и фактических задач региона и поддержания конкурентных позиций [1].

Регион может быть рассмотрен в разрезе товара ввиду наличия у товара такого основного свойства, как полезный эффект и ценность для потребителя.

На основе концепции комплекса маркетинга товарными характеристиками выступают четыре группы арсеналов средств маркетинга:

- продукт - совокупность характеристик, которыми обладает тот или иной товар, подлежащий предложению потребителю и выпускаемый предприятием;

- цена - денежная сумма, которую уплачивает потребитель за право пользование товаром в собственности;

- место - расстояние, которое необходимо преодолеть товару, чтобы быть доставленным от поставщика конечному потребителю;

- продвижение - набор действий, при помощи которых происходит информирование потребителей конкретных товаров об их отличительных характеристиках, степени полезности и наличии.
Так как комплекс маркетинга (4P) является универсальным, он может быть использован для любого товара. Основной задачей комплекса маркетинга является постоянный мониторинг товарных характеристик и выполнение действий, направленных на продвижение товара. В конечном итоге происходит разработка стратегических решений, направленных на повышение потребительской ценности товара, и, как следствие, увеличение прибыли.

На основании утверждения о возможности рассмотрения региона в товарном аспекте имеет место быть выделение регионального комплекса маркетинга (рисунок 1), базирующегося, соответственно, на специфике регионов.

1. Региональный продукт представляет собой один из основополагающих компонентов маркетингового потенциала региона. Являясь ядром маркетингового потенциала региона, региональный продукт лежит в базисе маркетингового процесса, без которого, в свою очередь, процесс дискуссии о маркетинге региона лишен смысловой нагрузки.

Региональный продукт в отношении маркетингового потенциала региона выступает в качестве ресурса. Характеристикой регионального продукта является показатель валового регионального продукта (ВРП). ВРП подводит итог значений всех элементов экономического процесса и является совокупным показателем экономической деятельности региона. В показателе ВРП находит отражение стоимость товаров и услуг, выпущенных некоторым количеством единиц экономической деятельности за отчетный период в ценах конечного покупателя [3]. 


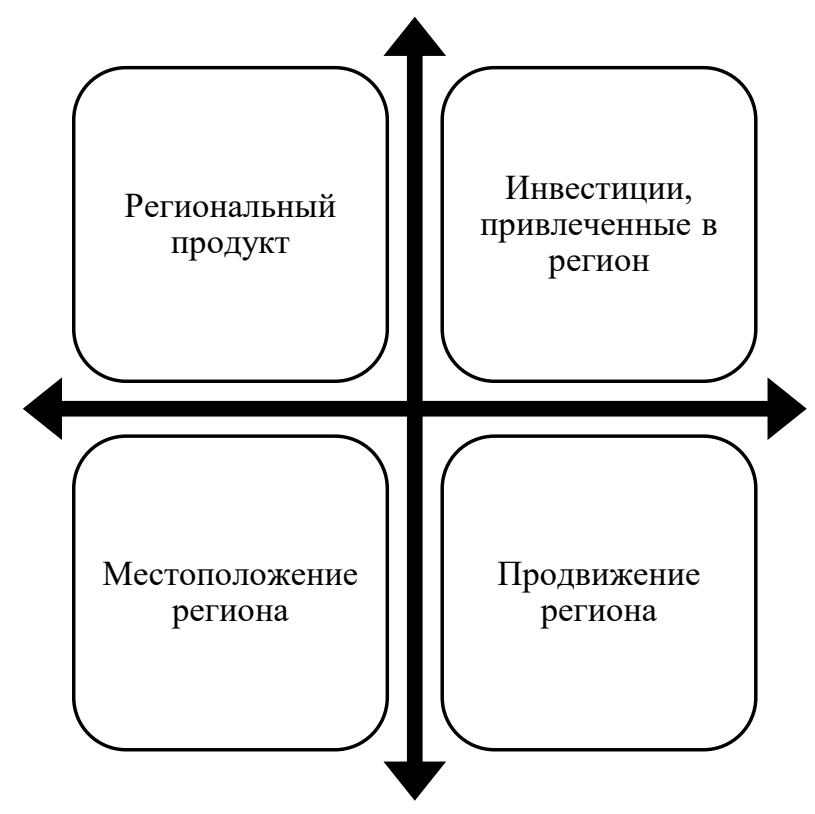

Рисунок 1. Региональный комплекс маркетинга [2]

2. Инвестиции, привлеченные в регион, являются основным источником формирования способностей региона по реализации региональных ресурсов и их модерации в региональный продукт. Они также предоставляют региону возможность по наращению ресурсной базы, модернизации способов производства и совершенствованию методологической базы продвижения регионального продукта, методов продвижения регионального продукта и улучшения его качества. При рассмотрении инвестиций, привлеченных в регион с позиции маркетингового потенциала региона, они играют роль способности региона. Региональный инвестиционный фонд будет являться основным показателем инвестиций, привлеченных в регион. Региональный инвестиционный фонд включает в себя совокупность таких элементов, как:

1) Инвестиции в основной капитал региона, являющиеся совокупностью расходов, направленных на повышение первоначальной стоимости объектов.

2) Доходная часть бюджета региона текущего года, состоящая из остаточного количества средств на конец прошлого года.

3) Прямые иностранные инвестиции в регион, характеризующиеся средствами иностранных инвесторов, которые были вложены в регион [4].
3. Местоположение региона является постоянным и неизменным для региона и привлекает определенное количество туристов и местных жителей, способствующих распространению маркетинговой информации о регионе, формированию и поддержанию имиджа региона. Местоположение региона в аспекте маркетингового потенциала региона относится к базовым ресурсам, изменение которого не представляется возможным, но улучшение состояния возможно. Местоположение региона может быть охарактеризовано при помощи совокупности показателей по водному, наземному, воздушному и подземному транспорту. Среди показателей по представленным видам транспорта можно выделить: протяженность путей, пассажиропоток, грузооборот, количество направлений авиаперелетов [5].

4. Продвижение региона состоит в степени эффективности организации ведения регионального маркетинга. Основная цель грамотного регионального продвижения заключается в ускорении процесса доставки товара от производителя к потребителю. Также региональное продвижение способствует повышению степени узнаваемости региона. В аспекте маркетингового потенциала региона региональное продвижение представляет собой способность региона, благодаря которой происходит процесс достав- 
ки товара от производителя к потребителю Для характеристики регионального продвижения предполагается использование таких показателей, как: туристический поток и миграция рабочего населения [6].

Для наглядности представим в виде рисунка модель компонентов маркетингового потенциала региона (рисунок 2).

На основе предложенной модели компонентов маркетингового потенциала региона можно предложить новый методический подход к оценке маркетингового потенциала региона.

Прежде всего необходимо будет составить таблицу, содержащую всю необходимую информацию не только о компонентах маркетингового потенциала региона, но и о характеристике выделенных в модели компонентов. Данные, заносимые в таблицу, являются официальными и предоставляются службой статистики каждого конкретного региона (табл. 1).

В дальнейшем на основе составленных таблиц необходимо будет построить лепестковую диаграмму (рисунок 3). Количество показателей, занесенных в таблицу, определяет количество осей лепестковой диаграммы.

Совокупное значение маркетингового потенциала региона будет равно площади фигуры, полученной на лепестковой диаграмме.

Предполагается воспользоваться следующим алгоритмом расчета площади фигуры:

- выявление значения угла, образованного двумя осями путем отнесения 360 к количеству осей на лепестковой диаграмме;

- расчет площадей всех треугольников, находящихся между близлежащими осями путем нахождения половины произведения значений двух находящихся рядом осей на синус угла, между ними;

- суммирование полученных площадей треугольников - нахождение совокупного значения маркетингового потенциала региона за конкретный временной интервал.

K преимуществам предложенного методического подхода к оценке маркетингового потенциала региона можно отнести: простоту использования, наглядность, возможность управлением маркетингового потенциала региона как в разрезе совокупного показателя, так и отдельно по каждой из характеристик, объективность оценки, емкость.

K возможным недостаткам предложенного методического подхода к оценке маркетингового потенциала региона можно отнести возможные трудности, связанные с поиском численных выражений некоторых компонентов маркетингового потенциала региона в статистических ежегодниках, находящихся в открытом доступе.

Предложенный методический подход $\mathrm{k}$ оценке маркетингового потенциала региона может быть применен по трем сценариям:

1. Частно-инвестиционный сценарий - в целях ведения бизнеса в регионе для наглядной оценки инвесторами региональных возможностей.

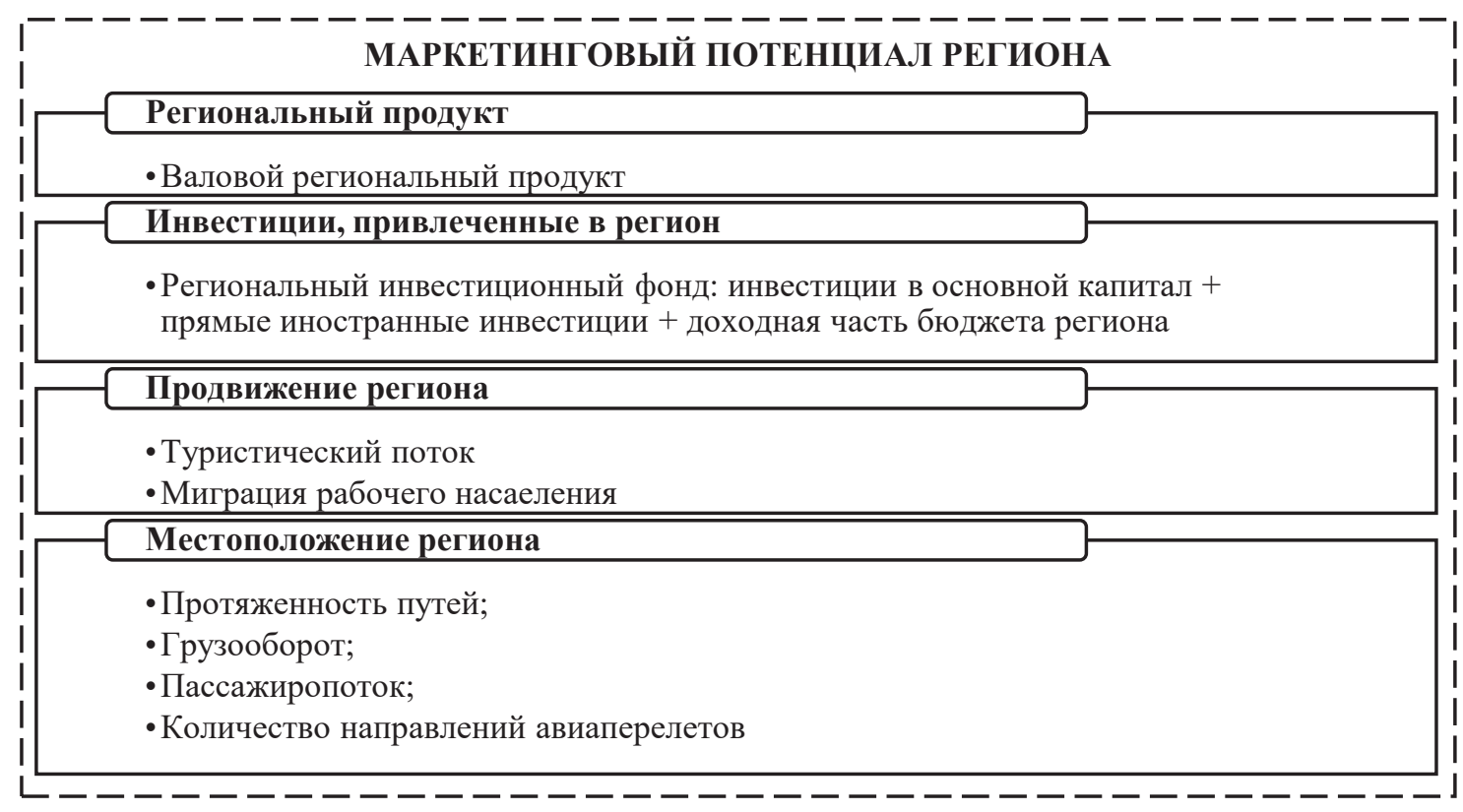

Рисунок 2. Модель компонентов маркетингового потенциала региона $[7,8,9]$ 
Таблица 1. Показатели маркетингового потенциала региона

\begin{tabular}{|c|c|}
\hline Наименование показателя & Значение за 20_г. \\
\hline \multicolumn{2}{|c|}{ Компонент 1} \\
\hline \multicolumn{2}{|l|}{ Показатель 1} \\
\hline \multicolumn{2}{|l|}{ Показатель 2} \\
\hline \multicolumn{2}{|l|}{...................... } \\
\hline \multicolumn{2}{|l|}{ Показатель n } \\
\hline \multicolumn{2}{|c|}{ Компонент 2} \\
\hline \multicolumn{2}{|l|}{ Показатель 1} \\
\hline \multicolumn{2}{|l|}{ Показатель 2} \\
\hline \multicolumn{2}{|l|}{.................. } \\
\hline \multicolumn{2}{|l|}{ Показатель n } \\
\hline \multicolumn{2}{|c|}{ Компонент 3} \\
\hline \multicolumn{2}{|l|}{ Показатель 1} \\
\hline \multicolumn{2}{|l|}{ Показатель 2} \\
\hline \multicolumn{2}{|l|}{.................... } \\
\hline \multicolumn{2}{|l|}{ Показатель n } \\
\hline \multicolumn{2}{|c|}{ Компонент 4} \\
\hline \multicolumn{2}{|l|}{ Показатель 1} \\
\hline \multicolumn{2}{|l|}{ Показатель 2} \\
\hline …............... & \\
\hline Показатель n & \\
\hline
\end{tabular}

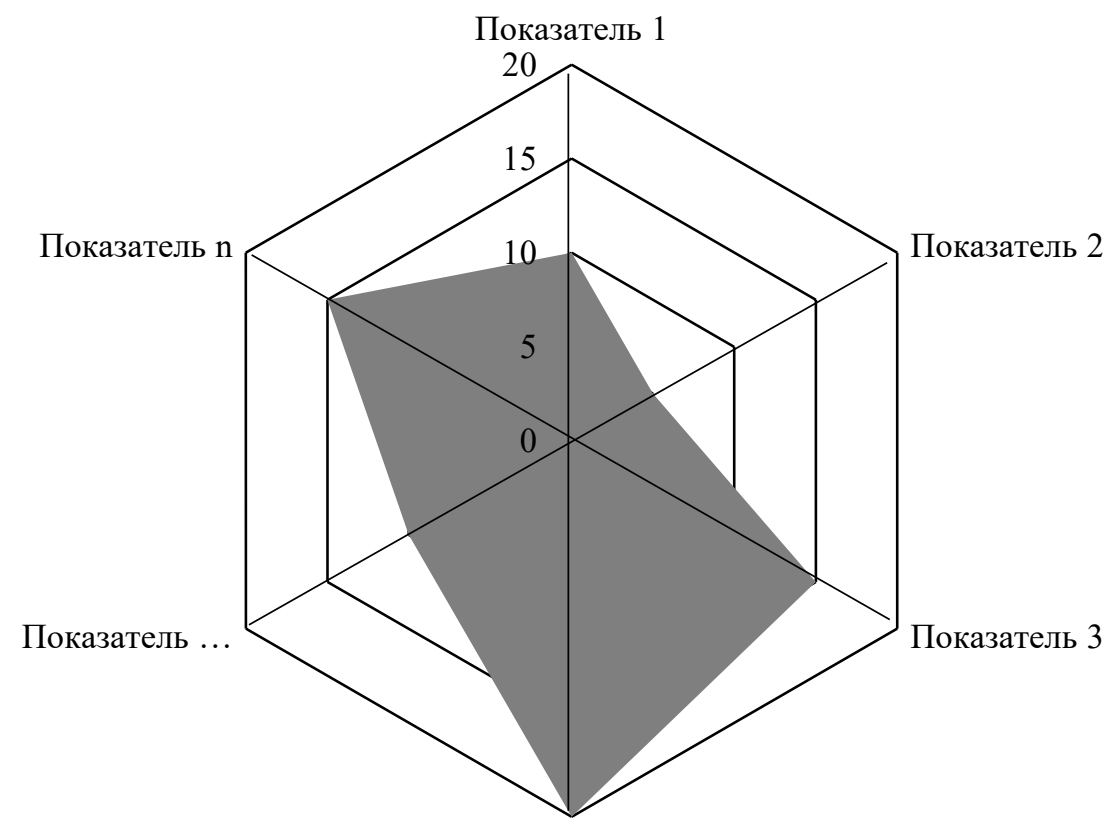

Показатель 4

Рисунок 3. Лепестковая диаграмма для расчета значения показателя маркетингового потенциала региона $[10,11]$ 
2. Государственный сценарий - в целях осуществления государственной политики. Возможно внедрение показателя маркетингового потенциала региона в качестве индикатора регионального развития.

3. Внутримиграционный сценарий - в целях улучшения позиции региона в глазах не только местных жителей, но и туристов.

Подводя итоги, можно заключить, что 4P регионального маркетинга состоит из регионального продукта; инвестиций, привлеченных в регион; местоположения региона и продвижения региона.

Каждый элемент 4Р региона состоит из определенных показателей, которые в свою очередь отождествляются с маркетинговыми ресурсами или способностями.

Регион является специфическим товаром, позиционирование региона лежит в основе функций регионального маркетинга и позволяет помогает региону поддерживать конкурентоспособность. Маркетинговый потенциал региона представляет собой совокупность маркетинговых ресурсов и способностей региона, определяющихся маркетинговым региональ- ным комплексом и обеспечивающих поддержание конкурентоспособного состояния и устойчивого развития региона на основе его целей, и маркетинговый потенциал региона характеризуется выделением основополагающих сильных сторон региона. На основе данных утверждений можно заключить, что маркетинговый потенциал региона - это характеристика позиции региона, которую он занимает на настоящее время, исходя из значений его ресурсов и способностей, представляющих собой элементы комплекса регионального маркетинга.

В разрезе ресурсов предполагается рассмотрение регионального продукта и местоположения региона, а в разрезе способностей - инвестиций, привлеченных в регион, и продвижения региона.

Предложенный методический подход к оценке маркетингового потенциала региона базируется на разработанной модели компонентов маркетингового потенциала региона и является универсальным для любого региона. Также существуют как минимум три сценария его практического применения.

\section{Библиографический список}

1. Панкрухин, А. П. Маркетинг территорий / А. П. Панкрухин.- СПб.: Питер, 2006. - 416 с.

2. Котлер, Филип. Основы маркетинга. Краткий курс [Текст]: [перевод с английского] / Филип Котлер.- Москва; Санкт-Петербург: Диалектика, 2019.-488 с.

3. Актуальные проблемы организации производства, маркетинга и менеджмента //Колл. моног. Ростов-наДону. Изд-во: ДГТУ. 2012. 176 с.

4. Банк России / [Электронный ресурс]. - Режим доступа: https://cbr.ru/statistics/macro_itm/svs/meth-kom-di/

5. Официальный сайт Федеральной службы государственной статистики / [Электронный ресурс].- Режим доступа: http://www.gks.ru/

6. РБК статистики / [Электронный ресурс].- Режим доступа: https://www.rbc.ru/economics/21/07/2020/5f0ece4 39a79470d37b66efc

7. Ц Целых, Т. Н. Маркетинг территории: теоретические подходы / Т.Н.Целых, В. Г. Воронин // Проблемы современной экономики. - 2011.- № 4.- С. 232-235.

8. Горелова, Т. П. Маркетинговый потенциал региона / Т. П. Горелова // Вестник Академии. - 2016. - № 4.- С. 21-25.

9. Толстых Д. В. Маркетинговый потенциал как фактор социально-экономического развития территории: автореф. дис. кан. экон. наук. М., 2013.

10. Капустина, И.В. Разработка методики оценки экспортного потенциала региона / И. В. Капустина, Э.А. Назарова // Неделя науки СПбПУ: Материалы научной конференции с международным участием. Лучшие доклады, Санкт-Петербург, 13-19 ноября 2017 года.-Санкт-Петербург: Федеральное государственное автономное образовательное учреждение высшего образования «Санкт-Петербургский политехнический университет Петра Великого», 2018.- С. 324-327.

11. Кхалаф, К. З. Инвестиционная концепция маркетингового потенциала региона / К. З. Кхалаф, И. Ю. Мошкин, Э.А.Назарова // Петербургский экономический журнал.- 2020.- № 4.- C. 75-81.- DOI 10.24411/23075368-2020-10040. 